\title{
PESQUISA PÓS-QUALITATIVA E RESPONSABILIDADE ÉTICA: NOTAS DE UMA ETNOGRAFIA FANTASMÁTICA ${ }^{1}$
}

\author{
POST-QUALITATIVE RESEARCH AND ETHICAL RESPONSIBILITY: NOTES ON A \\ PHANTASMATIC ETHNOGRAPHY
}

\author{
INVESTIGACIÓN POSCUALITATIVA Y RESPONSABILIDAD ÉTICA: NOTAS SOBRE \\ UNA ETNOGRAFÍA FANTASMÁTICA
}

\author{
Elizabeth Fernandes de Macedo \\ Universidade do Estado do Rio de Janeiro - Brasil \\ Paulo de Tássio Borges da Silva \\ Universidade Federal do Sul da Bahia - Brasil
}

\begin{abstract}
Resumo: Este texto apresenta reflexões metodológicas do grupo de pesquisa "Currículo, cultura e diferença", cujo foco é a investigação de políticas curriculares e seus efeitos sobre os processos de circulação da diferença. Para tanto, partimos do diálogo com a pesquisa "Paisagens e Fluxos Curriculares Pataxó: processos de hibridização e biopolítica", que buscou repensar as possibilidades da etnografia na pesquisa pós-estrutural em educação. Rasurando e ressemantizando o itinerário de construção científica da Antropologia com foco na pesquisa cultural, buscamos discutir a potencialidade de etnografias fantasmáticas para a pesquisa pós-qualitativa em educação. Numa abordagem flexionada por perspectivas pós-estrutural e pós-colonial, refletimos sobre a potência da etnografia fantasmática na contrução de um texto autobiofictício que busca responder de forma ética à interpelação da alteridade enquanto somos afetados por fantasmas espectrais. Nesse sentido, buscamos exemplificar e discutir como vimos buscando embaralhar as normas de composição de "verdades" e realidades, tratando-as as como fluxos de ficções complexos.
\end{abstract}

Palavras chave: Pesquisa Pós-Qualitativa; Etnografia Fantasmática, Currículo.

Abstract: This paper brings methodological reflections from the research group, "Curriculum, culture and difference," whose focus is the investigation of curricular policies and their effects on the circulations of difference. To do so, we dialogue with the research portrayed in "Pataxó Landscapes and Curriculum Flows: Hybridization processes and biopolitics," which sought to rethink the possibilities of ethnography in post-structural research in education. Erasing and re-semantizing the scientific itinerary of anthropology focusing on cultural research, we then examine and discuss the potential of phantasmatic ethnographies for post-qualitative research in education. In an approach inflected by post-structural and post-colonial perspectives, we reflect on the potentialities of phantasmatic ethnography in the construction of an autobiofictitious text, which seeks to ethically respond to the questioning of otherness as we simultaneously are affected by spectral ghosts. In this sense, we intend to exemplify how we have been seeking to shuffle the norms of composition of "truths" and realities, treating them as flows of complex fictions.

Keywords: Post-qualitative Research; Phantasmatic Ethnography; Curriculum.

${ }^{1}$ Pesquisas realizadas com financiamento do CNPq e da FAPERJ. 
Resumen: Este artículo trae reflexiones metodológicas del grupo de investigación "Currículum, cultura y diferencia", cuyo foco es la investigación de las políticas curriculares y sus efectos en las circulaciones de la diferencia. Para ello, dialogamos con la investigación plasmada en "Paisajes y flujos curriculares de Pataxó: procesos de hibridación y biopolítica", que buscaba repensar las posibilidades de la etnografía en la investigación postestructural en educación. Borrando y re-semánticamente el itinerario científico de la antropología centrado en la investigación cultural, luego examinamos y discutimos el potencial de las etnografías fantasmáticas para la investigación poscualitativa en educación. En una aproximación con inflexiones de perspectivas postestructural y poscolonial, reflexionamos sobre las potencialidades de la etnografía fantasmática en la construcción de un texto autobioficticio, que busca responder éticamente al cuestionamiento de la alteridad ya que simultáneamente nos afectan fantasmas espectrales. En este sentido, pretendemos ejemplificar cómo hemos estado buscando barajar las normas de composición de "verdades" y realidades, tratándolas como flujos de ficciones complejas.

Palabras clave: Investigación Poscualitativa; Etnografia Fantasmática; Curriuclum.

\section{Introdução}

Neste texto, partimos de preocupações metodológicas que têm conduzido o trabalho do grupo de pesquisa "Currículo, cultura e diferença", cujo foco está na investigação de políticas curriculares recentes como textos normativos com efeitos sobre os processos de circulação da diferença. Nas últimas duas décadas, de certo modo difratando ${ }^{2}$ o movimento do campo do currículo no país, vimos nos tornando cada vez mais céticos das promessas da teoria crítica e ampliando nosso diálogo com perspectivas pós-estruturais. Passaram a nos interessar filósofos da irrealizabilidade, ou seja, aqueles para quem as utopias críticas [universais] são aporéticas, sua plena realização seria a sua morte. Nos termos de Butler (2000, p. 39), "o que se mantem “irrealizado" pelo universal constituem-no essencialmente". Ao longo dos anos, nosso diálogo teórico com nomes como Bhabha, Derrida, Appadurai e, mais recentemente, Butler se intensificaram ${ }^{3}$, lançando-nos na compreensão do político como um jogo incessante de intervenção, disrupção, deslocamento. Talvez seja relevante citar nossa resistência à aproximação com Deleuze, autor que, no entanto, vai se insinuar em alguns dos pesquisadores com os quais construímos este texto.

Parte considerável deste caminho foi aberto pelas pesquisas de doutorado desenvolvidas no grupo. Sem exceção, elas lidam, por variados ângulos, com a temática da diferença, com o desejo de "desconstruir [os] modos mais perversos de lógica que sustentam formas de racismo

\footnotetext{
${ }^{2}$ Preferimos o termo difratar, como o fazem Haraway (1997) e Barad (2007), para dar conta de um efeito diverso do expresso pelo termo refletir, de uma prática para, em estilo derridiano, "reconfigurar topologicamente as conexões", “fazer a diferença” (Barad, 2007, p.381).

3 São também relevantes para o grupo as contribuições de Ball, Laclau e Mouffe no estudo das políticas curriculares, autores que, ao nosso ver, buscam dar uma inflexão pós-estrutural a demandas críticas do marxismo.
} 
e antropocentrismo" (BUTLER, 2018, p.44). Optamos por manter, propositalmente, na citação de Butler a alusão ao racismo, ainda que muitos de nós não tratemos de questões raciais, entendendo o termo na definição que lhe é dada por Souza (2017): “a separação ontológica entre seres humanos de primeira classe e seres humanos de segunda classe" (s/p). Teses lidando com políticas curriculares para sujeitos negros, indígenas, LGBTQIA+ nos impuseram outras visões de assuntos com os quais sempre lidamos, assim como novas temáticas. Conforme íamos nos voltando mais e mais para as práticas de esgarçamento de discursos normativos, questões como subjetivação e reconhecimento, por exemplo, se tornaram mais candentes e passaram a constituir parte importante das reflexões do grupo. Por outro lado, ao mesmo tempo em que tratar a questão da diferença sem sucumbir à linguagem identitária ou às políticas de identidade tornava-se central para o grupo, a escalada conservadora no país e no mundo tornava a empreitada mais copplexa. Se continuamos buscando respostas fora da ideia de identidade, vimo-nos impelidos a ser ainda mais cuidadosos a medida que as políticas públicas alicerçadas em tal ideia - e que, nos termos de Butler, tornam a vida de muitos mais vivível - passaram a ser objeto de fortes ataques.

Não é, no entanto, apenas o movimento teórico da pesquisa que tem nos apresentado desafios. Ao nos envolvermos mais e mais com os efeitos da políticas em termos de subjetivação, fomos lançados no campo dos estudos classicamente denominados "empírica", estudos que se lançam sobre a "realidade" buscando entendê-la ou contruir "verdades", mesmo que perspectivadas, sobre ela. Alguns de nós se moveram pelas trilhas da etnografia, outros pela autobiografia, outros ainda pelo que se poderia chamar de pesquisa participativa-ação. Nem todos quiseram se comprometer com os nomes clássicos, usaram apenas termos como estudo de caso ou o genérico estudo qualitativo. Todos, no entanto, foram e seguem sendo desafiados pela questão que apresentamos neste texto: se a inflexão pós-estrutural de nossas pesquisas rejeita o "representacionismo", como podemos lidar com os "dados" como condição de comprovação de realidades e vínculos, legitimados como condição de construção de uma pesquisa em educação? É possível tomar os "dados empíricos” como origem daquilo que será dito em nossas pesquisas? Começamos a esboçar uma resposta, argumentando, com St. Pierre (2018) “que não é possível pensar ou 'usar' as produtivas análises fornecidas pelos 'pós' (...) com a metodologia qualitativa humanista convencional porque seus compromissos ontológicos e epistemológicos não se alinham” (p. 1046), o que a torna incomensurável com a guinada pósestrutural que foram assumindo nossas pesquisas.

A saída de St. Pierre (2017) de se voltar eminentemente para a pesquisa conceitual ou teórica não atende aos anseios de nosso grupo de pesquisa. Seguimos, de alguma forma, 
entrando em contato com ocorrências para, possivelmente, como indica Butler (2016) em entrevista recente, "registrá-las (em nível teórico) e depois tentar pressionar a sua descrição para possibilidades que estão além de um horizonte mais limitado". Quem sabe assim, como Britzman e Pitt lembravam em 2003, a pesquisa poderia provocar conhecimento, ao invés de representá-lo. Talvez pudéssemos tentar - e é no que temos apostado - pensar o "empírico" como uma interpelação da alteridade que exige uma resposta da ordem da loucura, uma decisão precipitada impossível e necessária (DERRIDA, 2010). Assim, uma tese ou um relatório seria, para nós, um texto performativo que responde a "ocorrências" ou a "dados" na urgência e tenta borrar os limites em que eles podem ser pensados ou teorizados.

Com isso, para alguns de nós - e possivelmente mais e mais -, a condição de experimento na escrita tem sido a opção pela ficção (RANNIERY, 2018), um experimento tecido em meio a bricolagens de paisagens despretensiosas e "assemblages" (YOUDELL, 2015). Novamente, fazer uma opção por inspirações fictícias em um momento em que a conjuntura política no Brasil caminha para retrocessos e ataques aos direitos e à democracia pode ser difícil. Mais, ainda, quando a ciência está no centro do debate, sendo desqualificada pelo negacionismo e substituída por fake news. Para nós, no entanto, fazer política é exatamente compor ficções que não podem ser representadas no que aí está, são elas que friccionam as "verdades" polarizadas e os desejos de normatizar currículos e subjetividades. Tais ficções, "irreconhecíveis de acordo com as normas dominantes, [são] obviamente reconhecív[eis] dentro do campo epistêmico aberto pelas formas contra-hegemônicas de conhecimento" (BUTLER, 2018, p.43).

Para trazer nosso argumento, optamos, neste texto, pelo contexto de discussão de uma pesquisa em currículo e diferença com Povos Indígenas, seus fulcros de afetações (FAVRETSAADA, 2005), rasuras, escapes e descontruções. Não o fazemos sem receio, porque "aceitar ser afetado supõe (...) que se assuma o risco de ver seu processo de reconhecimento se desfazer" (FAVRET-SAADA, 2005, p. 160) -, mas certos da necessidade de fazê-lo. Partimos do diálogo com a pesquisa "Paisagens e Fluxos Curriculares Pataxó: processos de hibridização e biopolítica", em que Silva (2019) buscou repensar as possibilidades da etnografia na pesquisa pós-estrutural em educação.

Utilizando-se das noções de paisagens e fluxos de Appadurai, o autor embaralhou as normas de composição de "verdades" e realidades, entendendo-as como fluxos de ficções complexos, composições de discursos nos mais distintos processos de significação. Nesse sentido, em nenhum momento da tese, aparecem "efetivamente" os dados de campo descritos em minúcias, como quer a boa etnografia, o que provocou estranhamentos da banca. É a 
formulação de uma das avaliadoras de que só entendeu a tese quando resolveu tomá-la como ficção, como uma etnogarfia fantasmática, que mobilizamos como condutora de nossa reflexão. A escrita ainda não tinha, até este momento, sido conscientemente pensada como ficção, mas a imagem agradou e pareceu merecer atenção do grupo de pesquisa. A expressão de desejos do grupo, na escrita de Silva (2019), deixara os dados e as ocorrências como fantasmas que habitavam uma narrativa sempre ficcional. Se essa é uma tarefa difícil em um ethos acadêmico marcado por etnografias densas - que privilegiam a descrição atenta e detalhada, profunda ou totalitária -, talvez, nos fluxos marginais da pesquisa em educação, ela seja possível.

O que propomos aqui é, portanto, partilhar e refletir sobre a potência do que passamos a chamar, graças à colega, de etnografia fantasmática. Iniciamos tentando rasurar e ressemantizar a Antropologia com foco na pesquisa cultural para discutir a potencialidade de etnografias fantasmáticas para a pesquisa pós-qualitativa em educação.

\section{Rasuras e Ressemantizações na Antropologia}

As pesquisas etnográficas na área de educação no Brasil se adensaram no final dos anos 1980 e, em especial, nas décadas seguintes, não tendo necessariamente a antropologia como referência direta. Muito do debate se originava nas críticas norte-americanas às metodologias quantitativas sem que isso implicasse propriamente uma mudança paradigmática, como propunham Guba (1990) em obra canônica neste debate. Ao contrário, a virada qualitativa foi marcada por uma série de adaptações de conceitos da pesquisa quantitativa, como bem exemplifica a compilação de texto de Lather (2017). Em muitos de seus trabalhos das décadas de 1980-90, a autora buscava redefinir termos como triangulação, validade, fidedignidade para desenhos metodológicos qualitativos, o que, de certa forma, também marcou a obra de Ludke e André (1986), referência inconteste na pesquisa qualitativa no Brasil. Ao descrever como viveu este momento de transição nos EUA, St. Pierre (2018) narra uma cena de anseios, ainda hoje, familiar a muitos de nós no Brasil:

Os movimentos sociais, organizados várias décadas após a Segunda Guerra Mundial, incentivaram-nos a abraçar o multiculturalismo e a diversidade; e, porque queríamos ouvir as vozes de todos e saber o que sabiam, inventamos novas metodologias para capturar conhecimentos subjugados. (...) Ao invés de ler dados estatísticos coletados por pesquisas e experimentos, nos quais aquilo que as pessoas pensam e sentem desaparecia nos números, nas tabelas e nos gráficos, nós recuperamos o corpo vivo - queríamos as pessoas vivas, de carne e osso, presentes. Queríamos conversar com elas face a face para ver, em primeira mão, como seus rostos e corpos eram quando descreviam as experiências diárias vividas. Nosso desejo era ver sua dor. Queríamos testemunhar, em primeira mão, sua opressão, rir e chorar com elas quando nos contavam suas histórias, ouvir suas vozes que vinham das profundezas, do coração, de sua interioridade. Nós queríamos observá-los em seus ambientes 
naturais como realmente eram. Queríamos chegar ao solo da verdade, à realidade das suas vidas cotidianas. Ansiávamos por nossas próprias experiências em "estar lá" com as pessoas no campo, estando presentes, sendo testemunhas do momento. Logo, se capturássemos com cuidado e, sistematicamente, registrássemos a realidade autêntica, nós poderíamos reproduzi-la, representá-la nas palavras, na descrição consistente, de modo que outros pudessem ler nossos textos e estar lá também. (ST. PIERRE, 2018, p. 1050).

A aproximação com a antropologia foi se ampliando ao longo do tempo, em especial em pesquisas que discutiam a cultura, deslocando o debate da questão meramente metodológica. Se a aproximação com a antropologia permitia aprofundar a discussão em termos teóricos, ela não implicava em uma mudança no paradigma de uma pesquisa em busca da verdade científica, incontestável e comprovável pelas evidências do dado. No breve diálogo que queremos estabelecer com a antropologia, neste texto, argumentamos que ela se estabeleceu, desde os anos $1920^{4}$, como um itinerário de construção científica, em que a neutralidade etnográfica ganhou ênfase em detrimento da antropologia especulativa dos antropológos evolucionistas (JORDÃO, 2004). Tal movimento durou até o surgimento da antropologia pós-moderna, com a qual nos interessa dialogar neste texto.

Desde os anos 1920 até o questionamento do pensamento moderno às metanarrativas e leis universais, a antropologia foi capturada pela sedução de se tornar ciência, buscando se definir "por um domínio de objetos, um conjunto de métodos, um corpus de proposições consideradas verdadeiras, um jogo de regras e de definições, de técnicas e de instrumentos" (FOUCAULT, 1998, p. 30). Com isso, a etnografia perseguiu modelos de observação e verificação na construção de "verdades", performatizando entre "jogo de regras, métodos e técnicas" uma "ordem do discurso" científico (FOUCAULT, 1998). Para se aproximar da produção de fatos científicos, a antropologia precisou romper com a escrita literária e ficcional, de modo a explicitar objetividade, neutralidade, razão e verdade.

Interessa-nos, mais diretamente, o movimento da reflexão antropológica das décadas de 1960 e 1970, quando o conceito de cultura ganhou centralidade. Segundo Laraia (2001), neste momento, a perspectiva da cultura como um "sistema adaptativo" dividia espaço com propostas

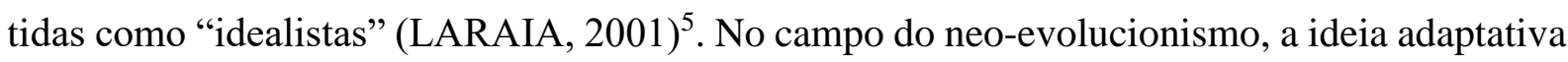

\footnotetext{
${ }^{4}$ É o trabalho "Argonautas do Pacífico Ocidental" de Bronislaw Kaspar Malinowski, publicado em 1922, marcou a construção da objetividade na antropologia: uma tentativa de reproduzir a realidade dos habitantes das Ilhas Trobriand na Nova Guiné a partir da pesquisa de campo. No entanto, já em 1883, Frans Boas produziu a primeira pesquisa in loco com observação direta dos esquimós na Ilha de Baffin, no Canadá, defendendo que o método etnológico era o método de observação.

${ }^{5}$ Fazem parte deste grupo Marvin Harris, Leslie White, Shalins, Carneiro, Rapaport e Vayda. Nesta análise estaremos nos detendo apenas às reflexões de Leslie White e Marshall Shalins, por entender que dão conta da crítica neo-evolucionista ao evolucionismo, assim como ilustram a transição do neo-evolucionismo à antropologia cultural.
} 
argumentava que "a passagem do estado animal para o humano ocorreu quando o cérebro foi capaz de gerar símbolos" (LARAIA, 2001, p. 56) e "que a complexidade da organização social de um povo era sinal de evolução cultural” (GUSSO, 2008, p. 208). Tendo Leslie White como um de seus expoentes, essa visão da antropologia defendeu o uso de métodos científicos para coletas de campo com vistas a análises dos fenômenos antropológicos (GUSSO, 2008). A partir do trabalho de Shalins ${ }^{6}$, um herdeiro de White, que passou a dialogar com Lévi-Strauss, no entanto, a perspectiva culturalista dos idealistas se consolidou no debate antropológico.

No contexto em que a cultura ganhou centralidade, sua definição passou a ser parte importante do debate, com o surgimento de abordagens que a viam como sistemas cognitivos, estruturais e simbólicos. Na definição de Laraia (2001, p.61), enquanto na primeira, a "cultura [era tomada como] um sistema de conhecimento: 'consist[ia] em tudo aquilo que alguém [tinha] de conhecer ou acreditar para operar de maneira aceitável dentro de sua sociedade"; na segunda, a cultura era "um sistema simbólico, (...) uma criação acumulativa da mente humana", como defendido por Levi-Strauss. Já como sistemas simbólicos - sem dúvida a interpretação mais prevalente na educação no Brasil -, a cultura era tomada como uma "teia de significados" (GEERTZ, 1989) construída a partir de pactos no governo de comportamentos, onde "todos os homens [eram] geneticamente aptos para receber um programa, e este programa [era] o que chamá[vamos] de cultura" (LARAIA, 2001, p. 62). Tal abordagem se desenvolveu como a antropologia interpretativa de Geertz, nos anos 1970.

Com a antropologia interpretativa, a discussão da cientificidade ganhou outro status no campo. Passou-se a questionar os princípios positivistas de "neutralidade e objetividade absolutas do conhecimento" e a defender que "o critério de cientificidade dev[ia] residir na estruturação lógica da pesquisa, na compreensão do fenômeno estudado" (JORDÃO, 2004, p. 38). A partir do paradigma hermenêutico, a antropologia passou a redefinir a compreensão do seu objeto de estudo, a cultura, enfatizando a etnografia e o campo de campo na contrução do seu empreendimento teórico. Assim, por um lado, a antropologia interpretativa buscava romper a reiteração com os ideias de objetividade e cientificidade. Por outro, no entanto, o vínculo com uma dada visão hermeneutica e a aposta em uma proposição dialógica de construção de intersubjetividade - marcada por dualismos ${ }^{7}$, manteve a busca por legitimação científica, tratando-a em uma perspectiva humanista. Assim, definindo-se como lugar de compreensão de

\footnotetext{
${ }^{6} \mathrm{O}$ autor se inicia como neo-evolucionista, com inspiração marxista, migrando posteriormente para o culturalismo.

${ }^{7}$ A antropologia interpretativa teve grande influência da hermenêutica de Wilheim Dilthey (1833-1911). Em busca de dar cientificidade às ciências interpretativas, Dilthey estabeleceu a oposição entre a compreensão da história, relativa às ciências do espírito, e a explicação da natureza, própria das ciências naturais. Assim, a produção do conhecimento se daria de formas distintas, numa diferença entre explicar e compreender, decorrente das distinções entre os estatutos natureza e espírito.
} 
culturas, como ciência interpretativa em busca de significados, a antropologia continuava reiterando um fazer da pesquisa alicerçado na produção do fato científico, possibilitada por uma interpretação etnográfica densa, que, muitas vezes, está esmiuçada em textos descritivos, frágeis de interpretação. Mesmo as perspectivas relativistas, que descreviam e reconstruíam as realidades culturais a partir do ponto de vista do nativo (o outro), não destituíram a autoridade etnográfica do fato. Apenas com a chamada antropologia pós-moderna - "meta-etnografia" ou "meta-antropologia", a "etnografia experimental" e a "vanguarda pós-moderna" (REYNOSO, 1991) - o modelo etnográfico de produção de "verdades" começou a ser borrado. Da forma como o movimento foi enunciado por Tyler (2016), a representação dava lugar à evocação, e o texto cedia lugar ao discurso:

O ponto central de "evocar", ao invés de "representar", é que isso liberta a etnografia da mimesis e do modo inadequado de retórica científica que requer "objetos", "fatos", "descrições", "induções", "generalizações", "verificação", "experimento", "verdade" [dados] e conceitos semelhantes que, a não ser como inovocações vazias, não têm qualquer paralelo nem na experiência do trabalho de campo etnográfico nem na escrita de etnografias. (TYLER, 2016, p. 193).

Com a "meta-etnografia" ou "meta-antropologia", a literatura, afastada da escrita etnográfica com o intuito de tornar a antropologia uma disciplina legítima e científica, é resgatada. Como define Reynoso (1991, p.28), "seu objeto de estudo não é a cultura etnográfica, mas a etnografia como gênero literário por um lado e o antropólogo como escritor pelo outro". Em diálogo com Foucault, de Certeau e Eagleton, Clifford (2016) vai criticar a exclusão da retórica, da ficção e da subjetividade que comandou a construção da cientificidade no campo antropológico. Para o autor, buscou-se com tais exclusões garantir, respectivamente, o "significado transparente e "evidente",; "o fato"; e "a objetividade" (p. 36).

A vertente da "etnografia experimental", , por sua vez, como indica a nomeação, focou sua atenção na redefinição das práticas etnográficas e da observação no trabalho de campo. A proposta de Tedlock de uma "etnografia dialógica" constitui um bom exemplo do questionamento da univocalidade do antropólogo em detrimento do "informante". O pesquisador advogava por uma polivocalidade que reconhecesse o dialogismo e a polifonia na representação das culturas (CLIFFORD, 2016) e inserisse outras vozes nas pesquisas. Em certa medida, trata-se de uma visão reiterada em pesquisas que operam com a ideia de "dar voz aos sujeitos".

\footnotetext{
${ }^{8}$ Inclui nomes como James Clifford, George Marcus, Dick Cushman, Marilyn Strathern, Robert Thornton, Michael Fischer, entre outros (as)

${ }^{9}$ Inclui nomes como Vincent Crapanzano, Kevin Dwyer, Paul Rabinow e Dennis Tedlock, entre outros.
} 
Diferentemente, a "vanguarda pós-moderna"10 não criticou a escrita antropológica tradicional nem reivindicou a renovação da literatura etnográfica. De forma mais radical, estava-se propondo, não apenas a crítica à escrita etnográfica, mas o "arrebentar dos gêneros literários acadêmicos” (REYNOSO, 1991, p. 29). Segundo o Reynoso (1991), a crítica desconstrutiva da "vanguarda etnográfica" mirou a ciência em geral e não propriamente o campo da antropologia. Como alternativa, ela propôs "uma antropologia irracional que reformul[asse] todo o projeto científico desde a origem" (p.28) por diferentes formas. Como exemplo, o autor (1991) destaca o trabalho de Taussig, em que é proposto "o esfacelamento do gênero e da autoridade etnográfica mediante o uso simbólico da montagem e colagem" (p. 28).

Por mais que classificações deste tipo sejam esquemáticas e apaguem as muitas distinções entre os autores - francamente em desacordo com a demanda pós-moderna por pluralidade e diferença -, elas nos permitem pontuar, de forma breve, tanto os vínculos da antropologia com o cientificismo, ainda hoje muito presentes, quanto perspectivas que os criticam. Ainda que tais críticas já estejam entre nós por muitos anos - o seminário que deu origem ao Writing Culture, editado por James Clifford e George Marcus, bíblia do pensamento pós-moderno na antropologia, data de 1984 -, muitas das "regras metodológicas" com as quais construímos nossas pesquisas etnográficas no campo da educação estão alicerçadas em perspectivas cientificistas e representacionais. Como vimos argumentando, isso nos parece um problema que as pesquisas com inflexão pós-estrutural precisam endereçar. Ao mesmo tempo, para muitos de nós que pesquisamos grupos culturais específicos não é possível deixar de considerar críticas postas por antropólogas feministas, ainda que tais críticas tivessem outro foco $^{11}$. Abu-Lughod (2018, p.215), por exemplo, argumenta que "ao defender novas formas de escrita - pastiche, diálogo, colagem, entre outras - [a estilização] desestabiliza a narrativa, as identidades dos sujeitos e as identificações". Não negamos que a opção por abordagens pósestruturais como as que propomos aqui e vimos usando em nossas pesquisas, complica o reconhecimento nos moldes em que ele vem sendo entendido e buscado em nossas políticas. Entendemos, também, a importância que demandas identitárias por reconhecimento tem tido na definição de políticas públicas que, na formulação de Butler, tornaram muitas vidas mais vivíveis. Ainda assim, advogamos a necessidade e urgência de pensar um outro reconhecimento que não se faça sobre os escombros da alteridade expulsa por muitos discursos normativos, entre eles, o da ciência moderna.

\footnotetext{
${ }^{10}$ Inclui nomes como Stephen Tyler e outros antropólogos no "Círculo de Rice".

${ }^{11}$ A argumentação de Abu-Lughod respondia à justificativa usada por Clifford para a ausência de antropólogas feministas na obra Writing Culture. O autor $(2018$, p.55) argumentou que "a etnografia feminista não produziu formas não convencionais de escrita ou reflexão desenvolvida sobre a textualidade etnográfica em si”.
} 


\section{Por uma outra etnografia na pesquisa em educação}

É no esteio das críticas pós-modernas ao cientificismo da antropologia que pretendemos assombrar a etnografia tradicional tal como ela vem sendo praticada em parte considerável da pesquisa em educação no Brasil ${ }^{12}$. Partimos de uma observação de Britzman (1995) em que a autora argumenta que a etnografia tem se fixado no "etno" e deixado de lado a discussão da "grafia". Nesse sentido, os bons textos etnográficos seriam aqueles capazes de trazer novas informações ao leitor, revelando um conhecimento cultural "real" de como são vividas as subjetividades dos habitantes de determinado lugar. Em tais pesquisas, opera-se como se os dados fossem algo natural - a serem coletados, gerados e interpretados - e não discursividades entrelaçadas de tensionamentos que moldam nossas maneiras de construir pesquisas e compreendê-las. As pesquisas qualitativas com inspiração etnográfica em educação estão, por certo, repletas de descrições detalhadas da "realidade cotidiana" das escolas, das salas de aula, com informações factuais que funcionam como "provas" do que se busca argumentar. No dizer de St. Pierre (2018), a pesquisa "empírica” ainda hegemônica no campo da educação, em muito marcada por inflexões críticas, baseia-se na "descrição iluminista e humanista do ser humano, da linguagem, do material, do empírico, do real, do conhecimento, do poder, da liberdade" p.1048). Em contraposição a tal visão, St. Pierre (2013) advoga por uma pesquisa pósqualitativa na qual se está consciente de que

[...] os dados aparecem, vêm a existir, existem (ou não) em uma estrutura metodológica, ontológica e epistemológica particular. O significado e função dos dados dependem do significado e função de uma constelação de outros conceitos que são imbricados, por exemplo, a realidade dos conceitos, as provas, os mandados, as reclamações, a razão, o conhecimento e, é claro, a verdade (ST. PIERRE, 2013, p. 223).

A opção teórica da autora para pensar uma pesquisa pós-qualitativa, não humanista, dialoga eminentemente com Deleuze. Assumir a crítica do autor à concepção arborescente de conhecimento - na qual os dados poderiam ser vistos como os frutos prontos para serem coletados de uma grande árvore com raízes profundas em solos firmes-, põe em questão não apenas a centralidade, mas a autonomia do dado na construção da ciência "verdadeira". A proposta de uma leitura rizomática, com redes de autômatos infinitos, apresenta o dado como uma multiplicidade deslocada e não-hierarquizada. Nessa leitura, há apenas heterogeneidade, os pontos não obedecem a uma lógica de conexão, podendo qualquer ponto estar conectado a outro; o rizoma está sempre sujeito a "linhas de fuga", apontando para novas direções e

\footnotetext{
${ }^{12}$ Destaque-se, recentemente, o livro organizado por Paraiso e Meyer (2014) e a seção temática organizada por Macedo e Ranniery (2018) no periódico Praxis Educativa.
} 
possibilidades, o rizoma é sempre um rascunho com entradas múltiplas, sendo acessado por pontos infinitos (GALLO, 2013). Ainda que nosso diálogo teórico, como grupo de pesquisa, não ocorra com o pensamento deleuziano, parece-nos tentador pensar a pesquisa como errância neste emaranhado.

Nos termos de Foucault (2009), um pouco mais próximos de como temos operado, os dados seriam enunciados, não uma coisa mostrada, construída e diagnosticada, mas a possibilidade de sentidos que, em redes de poderes e significações, são negociados e sancionados - aceitos ou não. Em tal perspectiva, seria "necessário entender a modalidade de existência de um conjunto de signos, modalidade que lhe possibilita ser algo mais que um simples conjunto de marcas materiais" (CASTRO, 2009, p. 137). O que pode ser "visto" ou "coletado" como dado, a verdade sobre a qual erigimos nossas interpretações, são apenas efeitos produzidos por múltiplos constrangimentos, ainda que nunca por eles determinados.

Se há alguma linha de aproximação que permita falar de uma etnografia pós-estrutural talvez seja o questionamento do desejo da presença que anima a clássica pesquisa que busca a "verdade" - ou a evidência que assume o caráter de fundamento -na experiência vivida cotidianamente pelos sujeitos. Nesse sentido, tal etnografia estaria pondo em questão a própria matriz de intelegibilidade da pesquisa clássica marcada, com frequência, "por descrições particulares dos sujeitos, da linguagem, do conhecimento, da realidade - conceitos que repousam sobre a metafísica da presença" (ST.PIERRE, 2009, p.224). A autoridade da experiência cotidiana ou daquilo que supostamente ocorreu e foi observado deixa de ser o fundamento que "oferece tanto um ponto de partida como uma explicação de tipo conclusivo a partir da qual poucas questões podem ou precisam ser formuladas" (SCOTT, 1991, p.790). Perguntas sobre o quão verdadeiros são os dados deixam de fazer sentido e respostas que apontam para o fato de serem versões interessadas da realidade são claramente insuficientes. Se não há presença, é preciso entender os dados empíricos como aquilo "sobre o que o conhecimento é produzido" (SCOTT, 1992, p.26).

De diferentes formas, estudos pós-qualitativos têm buscado levar a sério essa advertência. Apenas a título de exemplo, a própria Scott (1991) sugeria, em estudo já clássico ${ }^{13}$, a importância de que a problematização histórica não fosse substituída por evidências, autorizadas apenas por terem sido vividas e sentidas pelos sujeitos, em geral "minorias marginalizadas". Ao invés do foco na experiência dos indivíduos, a autora argumentava em favor de uma pesquisa que entendesse o sujeito como produzido pela experiência e pelo ato de narrá-la. Nesse sentido, a experiência seria tomada como discursiva: o vivido só faria sentido

\footnotetext{
${ }^{13}$ Este texto refere-se especificamente e de forma comparativa aos campos da história e literatura, mas tem sido
} utilizado em diferentes áreas, entre elas, estudos culturais, antropologia, estudos feministas e teoria queer. 
numa ordem discursiva que produz aquilo de que fala (FOUCAULT, 2009). De forma semelhante, ainda que distinta, St. Pierre (2009) também sugere que se desloque o foco dos indivíduos/sujeitos/participantes - de suas experiências e das evidências que eles produzem para o objeto de estudo, no caso de sua pesquisa e de muitas das que vimos realizando, a subjetividade. Para tanto, a autora propôs, naquele momento, borrar a noção de dado de modo a incluir não apenas o "empírico", mas também aquilo que frequentemente denominamos de referências ou teoria.

No entanto, não é apenas a autoridade do empirismo ou da ideia de que há algo a ser descrito que precisa ser desconstruída por uma etnografia pós-qualitativa ou pós-estrutural. Britzman (1995) chamava a atenção para a necessidade de também pôr em questão a aparente estabilidade de sentidos que surge como um dos efeitos da escrita. A descrição de Clifford sobre a etnografia explicita bem a preocupação da autora:

[...] a etnografia está, do começo ao fim, imersa na escrita. Essa escrita inclui, no mínimo, uma tradução da experiência para a forma textual. O processo é complicado pelas múltiplas subjetividades e constrangimentos políticos que estão acima do controle do escritor. Em resposta a estas forças, a escrita etnográfica encena uma estratégia específica de autoridade. Essa estratégia tem classicamente envolvido uma afirmação, não questionada, no sentido de aparecer como provedora da verdade no texto. (CLIFFORD, 2011, p. 221).

Para Britzman (1995), além da autoridade da escrita, há que se considerar também a presunção de que existe uma relação direta entre a leitura feita do texto e algo que ele revela, que ela denominou de autoridade da leitura ou da compreensão. Ou seja, o texto também se transforma num dado objetivo que permitiria o acesso ao real da experiência ou da cultura. Em conjunto, as autoridades da escrita e da leitura criam um acordo tácito de autoridade etnográfica - sempre traído - entre o participante, o etnógrafo e o leitor (BRITZMAN, 1995). Tal acordo precisa ser também posto em xeque pela etnografia pós-estrutural, de modo a que deixar visível que a pesquisa é um conjunto de práticas e de discursos que constrói, por meio de estratégias de autoridade diversas, aquilo que se propõe a representar. Assim, experimentações formais, de escrita, são, provavelmente, parte importante de uma virada pós-qualitativa ou pós-estrutural da etnografia.

Em diálogo com tal discussão, nosso caminho de pesquisa tem buscado produzir experiências distintas de escrita que apostam na ficção, como também o fizeram autores como Ratner (2004) e Cone (2013). A ideia tem sido brincar com os limites da promessa totalitária de verdade que a descrição detalhada e densa da realidade pretende produzir. Mesmo que se trate, como acreditamos, de uma promessa falaciosa, posto que derrapa na ambivalência da linguagem, não é sem importância que ela siga sendo sustentada por uma determinada forma 
de escrita acadêmica. Julgamos que é necessário rejeitar as metodologias cuidadosas do trabalho empírico que se propõe a resgatar a experiência cotidiana real, assim como as formas tradicionais de escrita. Não há nada a ser resgatado e o supostamente revelado é da ordem da ficção e assim deve ser apresentado.

A ideia de ficção não remete à não-existência, à irrealidade ou à mentira, "o fíccional não é compreendido como fictício, como pura invenção, mas como mobilização de estratégias narrativas" (NORONHA, 2014, p. 13). Trata-se de repensar uma ciência em que operações teóricas e metodológicas são percebidas como ficções construídas no ato de pesquisar. Elas não seriam materialidades ou verdades, seriam talvez espectros, sombras de possibilidades reflexivas que se esvaem com os discursos enunciados. Para Saer (2009):

Ao dar o salto em direção ao inverificável, a ficção multiplica ao infinito as possibilidades de tratamento. Não dá as costas a uma suposta realidade objetiva: muito pelo contrário, mergulha em sua turbulência, desdenhando a atitude ingênua que consiste em pretender saber de antemão como é essa realidade. Não é uma claudicação ante tal ou qual ética da verdade, mas uma busca de uma um pouco menos rudimentar (SAER, 2009, p. 2).

É neste jogo de enunciações discursivas que a composição de ficções se coloca na pesquisa como uma alternativa para evitar construir essencializações. Como destaca Raniery (2018, p.995), “fíccionar é a condição da pesquisa em currículo conferir à alteridade essa força animada que se move por meio de e move corpos e objetos", sem a qual parece impossível responder com responsabilidade ao chamado da diferença. Em época de negacionismo científico, talvez seja importante destacar que não pretendemos inverter a polarização entre verdade e ficção, conferindo primazia a segunda em detrimento da primeira. Uma tal empreitada seria "no plano que nos interessa, uma mera fantasia moral” (SAER, 2009, p. 2). Ao contrário, o que pretendemos é, por meio de composições fictícias e imaginadas de um porvir, assombradas por fantasmas e amarradas entre escapes e rasuras de convenções e articulações discursivas, criar a possibilidade do que Butler (2018) chama de abertura do campo epistêmico. Talvez assim possa ser definido o desejo normativo do nosso trabalho.

\section{Uma etnografia fantasmática como proposta Pós-Qualitativa}

Chegamos, assim, às ficções e paisagens de certezas construídas na pesquisa etnográfica conduzida por Silva (2019) ao longo de mais de uma década (13 anos) junto ao Povo Pataxó do Território Kaí-Pequi. Com tantos anos de vida na comunidade, não faltavam “dados”; um denso tecido a ser interpretado estava, sem dúvida, disponível para a produção dos usuais e clássicos estudos no campo da Educação Escolar Indígena, em sua maioria marcados pela "antropologia 
interpretativa" de Geertz (1989). Nunca é demais lembrar que antropologia e estudos com indígenas têm uma ligação histórica atávica, de modo que a etnografia se tornou, em muitos casos e não apenas na educação, o único lugar possível de verdade nesses estudos.

Incomodava-nos, no entanto, a ideia de resgatar a organização social, as cosmologias e as produções do Povo Pataxó com que Silva interagia como se fossem "dados" isolados e autônomos. Na perspectiva de que não há nada para ser resgatado, nos deixamos levar por caminhos que se tornaram paisagens, na acepção de Appadurai (2004), misturando muitos espectros, fugas e cenas etnográficas. Em pouco tempo, estávamos compondo paisagens com/entre o Povo Pataxó, das quais não estavam ausentes

os Kariri-Xocó, os Tupinikim, os Guarani e os Maracá. Fixar-se em um território é, possivelmente, uma grande lição da antropologia indígena, ele "define o objeto de estudo, [ainda que seja] mapeado pelo etnógrafo que está na paisagem, movendo-se e atuando dentro dela, [não se caracterizando como] um ponto transcendente e destacado" (MARCUS, 1994, p. 17). Transitar entre diferentes povos, ainda que em uma pesquisa com o Povo Pataxó do Território Kaí-Pequi, não se fixando no território, serviu para embaralhar a pesquisa, mas especialmente para evitar o fundacionalismo realista que caracteriza muito da etnografia com que estamos acostumados.

A partir da clássica expectativa que temos sobre a pesquisa e a escrita acadêmica - nós, também, visto que o fazemos de dentro de uma tradição que buscamos complicar -, pôr em questão a autoridade, não apenas do dado, mas do pacto etnográfico de que falava Britzman (1995), é uma empreitada com muitas idas e vindas. Talvez, ela tenha gerado um texto um tanto caótico, porque ausente de convenções realistas. Não se trataria, com certeza, do primeiro trabalho a ser criticado pela falta de realismo (Pratt, 2016) nem, muito menos, por ser confuso. Mesmo estranhando a facilidade com que julgamos o valor de um texto pela sua serventia, não nos furtamos às questões: para que e para quem serve um texto confuso? Com Marcus (1994), iniciamos por deixar claro que

[...] textos confusos não são modelos a serem seguidos, nem o tão esperado novo paradigma, nem uma conformidade vazia com a moda da radicalização [...] Eles são a base de teste - sempre uma mistura de forte engajamento de autores com o "que está acontecendo" com certas áreas de estudo e de um engajamento reflexivo igualmente forte com a sua própria formação acadêmica - na qual a ciência social está sendo refeita na ausência de modelos dominantes, paradigmas etc. A preocupação desses textos não é estreita e previsível, mas ampla e variada como as preocupações que delinearam as tradições das próprias ciências sociais. (MARCUS, 1994, p. 29).

Além de Marcus, nos juntamos a diversos outros autores (Britzman, 1995; Butler, 2016; Bhabha, 2001), para defender que a clareza está sempre, em algum nível, dominada por um horizonte de possibilidades reconhecível. Sem imaginar a viabilidade de renúncia total a tal 
clareza, entendemos que ela expressa o sucumbir a modelos capturáveis, não apenas da escrita [e da leitura, como lembra Britzman], mas do próprio fazer empírico da pesquisa. Um texto claro é já uma presa das restrições ao pensamento que permite ao leitor reconhecê-lo como um bom texto acadêmico, neste caso uma boa etnografia. A decisão por não reivindicar o lugar de etnógrafo na escrita, arriscando a confusão de trazer um emaranhado de paisagens de discursos fictícios nos soou, não o mais fácil, mas o compromisso necessário com um fazer ético da pesquisa: borrar acordos tácitos da autoridade etnográfica.

Recuperar a potência do emaranhado de paisagens e produções curriculares que têm se dado com os Pataxós e com outros povos indígenas nos pareceu uma forma de ecoar a advertência de St. Pierre (2009) de focar no objeto - Educação Escolar Indígena - e não nos sujeitos. Com isso, enfatizamos a compreensão de como essa educação vem sendo normatizada por dispositivos biopolíticos em distintos contextos e territórios. Interessava-nos, muito mais, criar formas de teorizar para além do horizonte dado do que capturar os acontecimentos. Vale ressaltar que o trânsito entre cenas etnográficas com vários povos indígenas não pretendeu capturar suas diferenças, reiterando a figura homogênea do "indígena". Como vem sendo denunciado pelos próprios povos, tal procedimento, em funcionamento inclusive em propostas curriculares para educação indígena, serve mais para o culto ao exótico do que para a enunciação da diferença. Em outra direção, o movimento que fizemos entre distintas cenas foi um exercício de ampliar o campo interpretativo, evitando fixá-lo, uma forma de construir rasuras e descontinuidades etnográficas.

Lidamos, ao longo do processo, com muitas questões que talvez já não merecessem ser trazidas neste momento, mas que o fazemos de forma um tanto quanto retórica. Podemos tomar a longa vivência de 13 anos junto ao Povo Pataxó como uma etnografia? Há registros detalhados do que foi vivido? Que "dados" ou registros evocar na concepção das paisagens e do emaranhado ficcional que íamos narrando? Como selecioná-los? E sobre os outros Povos (quais?), de onde vêm os registros que mobilizamos? Estas e muitas outras questões seguiram e seguem nos empurrando na direção do realismo humanista e do cientificismo mesmo quando estávamos determinados a evitá-los. Como evitar a metafísica da presença de uma experiência/cultura vivida a ser densamente narrada? Muitas ideias e estratégias foram emprestadas das tentativas de outros pesquisadores de fazer uma pesquisa pós-qualitativa. Produzir uma etnografia clássica para, em seguida, fazê-la estranha, desconstrui-la: parecia pouco, para ousar é preciso antes sucumbir? Esquecer o "dado", como vem propondo St. Pierre, na criação de uma pesquisa outra que incorpora a inflexão pós-estrutural? Seria possível esquecer o que nos impacta como se tivesse "efetivamente" acontecido, o que "testemunhamos" ou "experienciamos"? Com essas muitas questões, seguimos tentando "explorar uma forma de 
acolher, sem com isso domesticar, as implicações pós-estruturais para a metodologia de pesquisa em educação e em currículo" (MACEDO e RANNIERY, 2018, p. 942).

Nossa contribuição para tal acolhimento veio na forma da composição de paisagens fictícias provisórias, que não pretendem ser presença, domesticar ou servir de modelo. Os “dados" foram sendo pensados como vestígios, na linguagem de Derrida (2008), rastros de rastros sem origem:

O rastro é verdadeiramente a origem absoluta do sentido em geral. O que vem a afirmar mais uma vez, que não há origem absoluta do sentido em geral. $\mathrm{O}$ rastro é a différance que abre o aparecer e a significação. Articulando o vivo sobre o não-vivo em geral, origem de toda repetição, origem da idealidade, ele não é mais ideal que real, não mais inteligível que sensível, não mais uma significação transparente que uma energia opaca e nenhum conceito da metafísica pode descrevê-lo. (DERRIDA, 2008, p.80).

Ainda que tenhamos mantido a longa citação acima, interessa-nos mais especificamente a formulação de que "o rastro é a différance que abre o aparecer e a significação". Ou seja, no mesmo movimento, ele repete e difere, funcionando como uma abertura para o outro totalmente outro, para o "fora". Não há presença, mas um vir a ser constante e incapturável (DERRIDA, 2008). Assim, os "dados" - as cenas descritas em si, assim como as muitas crenças que nos constituem - são fantasmas vivos que nos acompanham, sem que possam ser ditos verdades ou mesmo representações. Apenas assombros fantasmagóricos que produzem movimento e estranhamento (heterogeneidade), borrando o dado-representação do que lá estaria. Não há evidências, mas a companhia espectral de fantasmas: escrever com ela se torna uma trabalhosa tarefa de resposta à alteridade, ao outro que aparecia para nós como cenas etnográficas. É importante dizer que o espectro "não se conhece, não por ignorância, mas porque (...) já não pertence ao controle do conhecimento. Pelo menos não pertence mais àquilo que pensamos entender com o nome de conhecimento" (DERRIDA, 1994, p.6). Por isso, possivelmente, nosso caminho - no início, um tanto quanto inconsciente - produziu ficções que gostamos de enxergar como uma tentativa de, mais propriamente, embaralhar a distinção entre a ficção e não ficção. Literatura? Talvez, "o lugar privilegiado de tudo 'dizer, tudo aceitar, tudo receber, tudo sofrer, tudo simular' (DERRIDA, 1998). (...) a literatura apontará a potência de ficção e de indeterminação de todo texto" (RODRIGUES, 2013, p.51). Um lugar que, segundo Rodrigues (2013) "serve aos seus propósitos éticos [de Derrida] de articulação entre ética e alteridade" (p.58).

Nesse sentido, o exemplo da tese de Silva (2019), escrita sobre e com o Povo Pataxó do Território Kaí-Pequi, é parte da trajetória de um grupo que vem buscando, não apenas criar experimentações pós-qualitativas de pesquisa em educação, mas ser responsivo à alteridade 
(MILLER e MACEDO, 2018). Nela, a opção foi sendo por falar de descontinuidades, de cenas misturadas e desarranjadas, de modo a construir um porvir de imaginários desconexos e fictícios. Como temos buscado defender, a escrita em si - um texto autobiofictício - se torna a resposta à alteridade que nos interpela na medida em que somos afetados por muitos fantasmas espectrais. Neste caso, não era mais uma escrita sobre o Povo Pataxó, mas sobre nossas mútuas afetações, uma resposta ao outro que nos interpela e que, por responsabilidade ética, não pode ser assimilado ou subsumido ao já dado. Como em outras teses, Silva (2019) tentou oferecer ao outro uma resposta impossível, mas necessária, porque "devida (...) antes de qualquer contrato, porque é vinda, a vinda do outro como singularidade sempre outra" (DERRIDA, 2010, p.49).

\section{REFERÊNCIAS}

ABU-LUGHOD, Lila. A Escrita contra a Cultura. Equatorial, Natal, v. 5, n. 8, jan/jun 2018, p. 193-226.

APPADURAI, Arjun. Dimensões Culturais da Globalização: a modernidade sem peias. Lisboa: Editorial Teorema Ltda, 2004.

BARAD, Karen. Meeting the universe halfway. Durham: Duke University Press, 2007.

BHABHA, Homi. O local da cultura. Belo Horizonte: Editora da UFMG, 2001.

BRITZMAN, Deborah. The Question of Belief: writing poststructural ethnography. In: Qualitative Studies in Education, v. 8, n. 3, 1995, p. 229- 238.

BUTLER, Judith. Restaging the Universal: Hegemony and the limits of formalism. In BUTLER, Judith; LACLAU, Ernesto; ZIZEK, Slajoj, Zizek. Contingency, hegemony, universality. London: Verso, 2000.

BUTLER, Judith. A conversation with Judith Butler, Paul North, and Jason Stanley. New York: Yale University. 2016. Disponível em: https://www.youtube.com/watch?v=aVo4T6PI77I. Acessado em 25 de maio 2021.

BUTLER, Judith. Corpos em aliança e a política das ruas. Rio de Janeiro: Civilização Brasileira, 2018.

CASTRO, E. Vocabulário de Foucault: Um percurso pelos seus temas, conceitos e autores. Belo Horizonte: Autêntica Editora, 2009.

CLIFFORD, James. A experiência etnográfica: antropologia e literatura no século XX. Organizado por José Reginaldo Santos Gonçalves. Rio de Janeiro: Editora UFRJ, 2011.

CLIFFORD, James. Introdução: Verdades Parciais. In: CLIFFORD, James e MARCUS, George. A escrita da Cultura: poética e política da etnografia. Rio de Janeiro: EdUERJ; Papéis Selvagens Edições, 2016. 
CONE, Elizabeth A. I am not that girl; this is not my narrative: contesting the discourses and practices that construct the subject. New York: Teacher College, Columbia University, 2013 (Tese de Doutorado).

DERRIDA, Jacques. Espectros de Marx. Rio de Janeiro: Relume-Demará, 1994.

DERRIDA, Jacques.Gramatologia. São Paulo: Perspectiva, 2008.

DERRIDA, Jacques. A força da lei. São Paulo: Martins Fontes, 2010.

FAVRET-SAADA, Jeanne. Ser afetado. Cadernos de Campo, n.13, 2005, p.155-161.

FOUCAULT, Michel. A ordem do discurso. São Paulo: Loyola, 1998.

FOUCAULT, Michel. Arqueologia do saber. Rio de Janeiro: Forense Universitária, 2009.

GALLO, Sílvio. Deleuze e a Educação. Belo Horizonte: Autêntica editora: Belo Horizonte, 2013.

GEERTZ, Clifford. A interpretação das Culturas. Rio de Janeiro: Editora Guanabara Koogan, 1989.

GUBA, Egon. The paradigm dialog. London: Sage Publications, Inc., 1990.

GUSSO, Helder Lima. Processos comportamentais identificados nas definições de cultura na antropologia: relações entre conceitos básicos de análise do comportamento e fenômenos sociais. Florianópolis: Programa de Pós-Graduação em Psicologia; UFSC, 2008 (Dissertação de Mestrado).

HARAWAY, Donna. Modest_Witness@Second_Millennium.FemaleMan@_Meets_

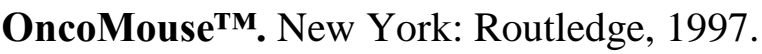

JORDÃO, Patrícia. A Antropologia Pós-Moderna: uma nova concepção da etnografia e seus sujeitos. In.: Revista de Iniciação Científica da FFC, v.4, n.1, 2004.

LARAIA, Roque de Barros. Cultura: um conceito antropológico. Rio de Janeiro: Zahar, 2001.

LATHER, Patti. (Post)Critical methodologies: the science possible after the critiques. New York: Routledge, 2017.

LÜDKE, Menga; ANDRÉ, Marli. Pesquisa em educação: abordagens qualitativas. São Paulo: EPU, 1986.

MACEDO, Elizabeth; RANNIERY, Thiago. E depois do pós-estruturalismo?: experimentações metodológicas na pesquisa em currículo e educação. In: Revista Práxis Educativa, Ponta Grossa, n. 13, n.3, Set./Dez., 2018, p. 941-947.

MARCUS, George E.. O que vem (logo) depois do Pós: o caso da Etnografia. In: Revista de Antropologia, v. 37, p. 7-34, 1994. 
MILLER, Janet L.; MACEDO, Elizabeth. Políticas públicas de currículo: autobiografia e sujeito relacional. In.: Revista Práxis Educativa, Ponta Grossa, n. 13, n.3, Set./Dez., 2018, p. 948-965.

NORONHA, Jovita Maria Gerheim. Ensaios sobre a Autoficção. Belo Horizonte: UFMG, 2014.

PARAISO, Marlucy; MEYER, Dagmar R. Metodologias de Pesquisas Pôs-Criticas em Educação. Belo Horizonte: Mazza Edições, 2014.

PRATT, Mary Louise. Trabalho de campo em lugares comuns. In.: CLIFFORD, James; MARCUS, George (Org's.). A Escrita da Cultura: poética e política da etnografia. Rio de Janeiro: EdUERJ; Papéis Selvagens, 2016, p. 63- 90.

RANNIERY, Thiago. Vem cá, e se fosse ficção? In.: Revista Práxis Educativa, Ponta Grossa, n. 13, n.3, Set./Dez., 2018, p. 982-1002.

RATNER, Andrew. Parallel lives, parallel litteracies: A reflexive life-history of an adult emerging reader and his teacher researcher. New York: Teacher College, Columbia University, 2004 (Tese de Doutorado).

REYNOSO, Carlos. Representación. El surgimento de la antroplogia posmoderna. México: Gedisa, 1991.

RODRIGUES, Carla. Paixões da literatura: Ética e alteridade em Derrida. Sapere Aude, v.4, n.7, $1^{\circ}$ sem. 2013, p. 47-59.

SAER, Juan José. O conceito de ficção. Sopro, n. 15, 2009, p. 1-4.

SAER, Juan José. O conceito de ficção. Revista Fronteira Z. São Paulo, n. 8, Jul., 2012.

SCOTT, Joan W. The Evidence of Experience. Critical Inquiry, v. 17, n. 4, 1991, p. 773-97.

SCOTT, Joan W. Experience. In J. Butler \& J.W. Scott (Eds.). Feminists theorize the political. New York: Routledge, 1992, p. 22-40.

SILVA, Paulo de Tássio B. Paisagens e fluxos curriculares Pataxó: processos de hibridização e biopolítica. Rio de Janeiro: Programa de Pós-graduação em Educação; Universidade do Estado do Rio de Janeiro, 2019 (Tese de Doutorado).

SOUZA, Jessé. A elite do atraso. Rio de Janeiro: Leya, 2017.

ST. PIERRE, Elizabeth A. Decentering voice in qualitative inquiry. In A. Jackson \& L. Mazzei (Eds). Voice in qualitative inquiry: Challenging conventional, interpretive, and critical conceptions in qualitative research. New York: Routledge, 2009, p. 221-236.

ST. PIERRE, Elizabeth A. Post Qualitative Inquiry: The next generation. In: N.K. Denzin \& M. D. Giardina (Eds.). Qualitative Inquiry in Neoliberal Times, 2017, p. 39-50.

ST. PIERRE, Elizabeth A. The appearance of Data. In.: Cultural Studies: critical methodologies, 2013, p. 223- 227. 
ST. PIERRE, Elizabeth A. Uma história breve e pessoal da pesquisa pós-qualitativa: em direção à "pós-investigação". In.: Revista Práxis Educativa, Ponta Grossa, n. 13, n.3, Set./Dez., 2018, p. 1044-1064.

TYLER, Stephen. Post-modern ethnography: from document of the occult to occult document. In: CLIFFORD, James e MARCUS, George. A escrita da Cultura: poética e política da etnografia. Rio de Janeiro: EdUERJ/ Papéis Selvagens Edições, 2016.

YOUDELL, Deborah. Theory assemblage and sociological education policy. In.: GULSON, Kalervo N.; CLARKE, Matthew; PETERSEN, Eva Bendix (Eds.). Education Policy and Contemporary Theory: implications for research. London: Routledge, 2015.

\section{SOBRE OS AUTORES:}

\section{Elizabeth Fernandes de Macedo}

Doutora em Educação, UNICAMP. Professora Titular da Universidade do Estado do Rio de Janeiro, Brasil. Atua no Programa de Pós-graduação em Educação e coordena o grupo de pesquisa "Currículo, cultura e diferença". Bolsista 1A CNPq, Cientista do Nosso Estado da FAPERJ e Procientista da UERJ. Correio eletrônico: bethmacedo@ pobox.com

(iD https://orcid.org/0000-0003-4886-8709

\section{Paulo de Tássio Borges da Silva}

Doutor em Educação, UERJ. Professor Adjunto da Universidade Federal do Sudoeste da Bahia. Atua no Programa de Pós-Graduação em Ensino e Relações Étnico-raciais (UFSB) e como professor convidado na Licenciatura Intercultural Indígena - Prolind/UFES. Coordena o grupo de pesquisa "Currículo, Diferença e Formação de Professorxs" (UFSB). Correio eletrônico: paulodetassiosilva@yahoo.com.br

(iD http://orcid.org/0000-0001-5328-7269 